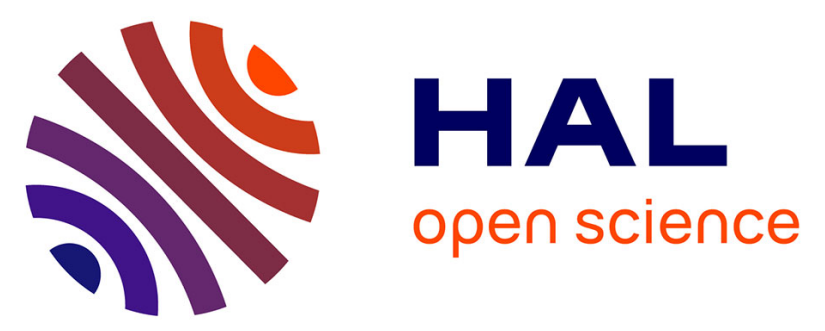

\title{
Seeing the wood for the trees: Applying the dual memory system model to investigate expert teachers' observational skills in natural ecological learning environments
}

Karin Stolpe, Lars Björklund

\section{To cite this version:}

Karin Stolpe, Lars Björklund. Seeing the wood for the trees: Applying the dual memory system model to investigate expert teachers' observational skills in natural ecological learning environments. International Journal of Science Education, 2011, pp.1. 10.1080/09500693.2011.561505 . hal-00704665

\section{HAL Id: hal-00704665 \\ https://hal.science/hal-00704665}

Submitted on 6 Jun 2012

HAL is a multi-disciplinary open access archive for the deposit and dissemination of scientific research documents, whether they are published or not. The documents may come from teaching and research institutions in France or abroad, or from public or private research centers.
L'archive ouverte pluridisciplinaire $\mathbf{H A L}$, est destinée au dépôt et à la diffusion de documents scientifiques de niveau recherche, publiés ou non, émanant des établissements d'enseignement et de recherche français ou étrangers, des laboratoires publics ou privés. 


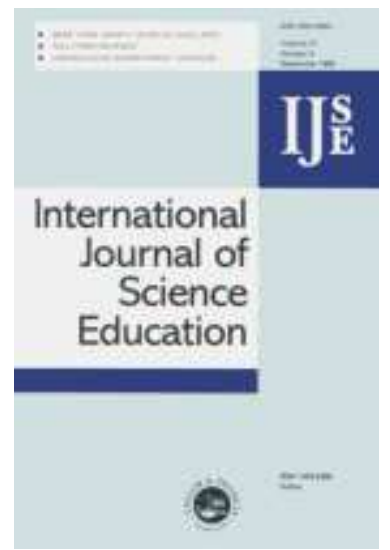

Seeing the wood for the trees: Applying the dual memory system model to investigate expert teachers' observational skills in natural ecological learning environments

\begin{tabular}{|r|l|}
\hline Journal: & International Journal of Science Education \\
\hline Manuscript ID: & TSED-2010-0421-A.R1 \\
\hline Manuscript Type: & Research Paper \\
\hline Keywords : & ecology education, teacher actions \\
\hline Keywords (user): & classification, pattern recognition, dual memory system \\
\hline
\end{tabular}

\section{SCHOLARONE}

Manuscripts 
Seeing the wood for the trees: Applying the dual memory system model to

\section{environments}

This study aims to investigate two expert ecology teachers' ability to attend to essential details in a complex environment during a field excursion, as well as how they teach this ability to their students. In applying a cognitive dual memory system model for learning we also suggest a rationale for their behaviour. The model implies two separate memory systems: the implicit, non-conscious, non-declarative system and the explicit, conscious and declarative system, respectively. This model provided the starting point for the research design. However, it was revised from the empirical findings supported by new theoretical insights. The teachers were video and audio recorded during their excursion and interviewed in a stimulated recall setting afterwards. The data was qualitatively analysed using the dual memory system model. The results show that the teachers used holistic pattern recognition in their own identification of natural objects. However, teachers' main strategy to teach this ability is to give the students explicit rules or specific characteristics. According to the dual memory system model the holistic pattern recognition is processed in the implicit memory system as an unconscious match with earlier experienced situations. We suggest that this implicit pattern matching serves as an explanation for teachers' ecological and teaching observational skills, Another function of the implicit memory system is its ability to control automatic behaviour and nonconscious decision-making. The teachers offer the students firsthand sensory experiences which provide a prerequisite for the formation of implicit memories that provides a foundation for expertise.

\section{Introduction}

The purpose of the present study is to describe and suggest a rationale of expert ecology teachers' ability to attend to essential details in a complex natural environment as well as how 
they teach this ability to their students. This ability is referred to in this paper as observational skill.

Natural environments, such as forests, consist of many features on different levels of scale. A typical forest is composed of plants, trees, flowers, animals and other objects. However, the forest as such, is not possible to recognize only by looking at the different constituents, for example the trees. Rather, we need to observe the forest as a "whole". In fact, research has shown that humans are able to categorize natural scenes rapidly, using what are known as "global properties" (Greene \& Oliva, 2009). For example, humans are able to discriminate a lake from a wood without effort, an achievement which has been hard to accomplish in a computer program. These findings suggest that the ability to categorize natural scenes is closely connected with an observational skill.

Teachers' observational skills in classrooms have been studied for many years, skills that have been shown to be strongly correlated with the length of teaching experience (Ericsson, 2006). By the same token, expert teachers have a better ability to interpret pupils' behaviour in the classroom than novice teachers (Berliner, 2001). Kerrins and Cushing (2000) have also identified differences between experts and novices observing the same classroom. This study used a stimulated recall setting where experienced and beginning principals first viewed a teaching episode, and were then asked questions about what happened in the classroom. The main difference between the novices and the experts was that the experts tended to observe the classroom from a broader, more interpretative perspective, whilst the novices tended to be more descriptive in their approach, which often missed the connectedness and coherence of classroom events. Another study reported that expert teachers were more receptive to both visual and auditory stimuli than novice teachers (Sabers, Cushing, \& Berliner, 1991). In this study, participants viewed three television screens, each showing a separate view from group work in progress in the classroom. The experts were 
found to scan all three monitors for meaningful events, while the novices were only able to look at one of the screens at a time. Even though these studies do describe that the skills develop with experience, they do not offer any explanation of why and how this happens.

In a more recent study, Ainley and Luntley (2007) suggested that "attention-dependent knowledge" helps the teacher to focus on what is important in a particular situation and what needs to be evaluated and acted upon. The authors also emphasised that this knowledge is neither reflected nor possible to verbalise. In support of the former, Johansson and Kroksmark (2004), revealed that experienced teachers showed more "automatic" behaviour in the classroom, a skill which they described as "intuition-in-action".

We will highlight two important aspects from the research on novice and expert teachers. Firstly, it seems like expert teachers have a "holistic overview" of the classroom during their practice. They also have an enhanced ability to attend to important but subtile aspects in the classroom. It could be sad that expert teachers have a better-developed observational skill than novices do. Through such well-developed skills, experienced teachers are able to manage their classrooms with little cognitive effort. In contrast, novice teachers tend to have difficulties in seeing the connectedness of classroom events since they are busy sorting out which details they should attend to.

Secondly, expert teachers seem to have the ability to react both quickly and appropriately in upcoming situations that require intervention. Noticeably, these actions are rapid, automatic, often not reflected upon, and even non-conscious.

The aspects highlighted above show that experts can act automatically and appropriately, based on their ability to attend to meaningful events in complex environments (Dreyfus \& Dreyfus, 1986). In this article, we shall develop the postulate that the skills that discern a novice from an expert could be explained in terms of a psychological dualprocessing model of cognition (Björklund, 2008; Evans, 2008). In this regard, our starting 
point for the research design presented in this work was the assumption that the dualistic psychological model could be used to explain experts' observational skills in natural ecological learning environments.

\section{Theoretical framework}

\section{A dual memory system model}

Dual-processing is a psychological model which implies that there are two different systems for reasoning, judgement and social behaviour. The concept of dual-processing is more than 40 years old. In a recent review, Evans (Evans, 2008) compares different researchers' descriptions of the two systems. Research in the fields of cognition and neuropsychology has confirmed that there are two biologically distinct memory systems in the human brain, namely the declarative and the non-declarative systems (Evans, 2008; Squire, 2004). By integrating results from research in psychology, neurophysiology and pedagogy, Björklund suggests that the dual memory system model is also applicable for learning (Björklund, 2007, 2008). He uses the terms implicit and explicit memory systems as synonyms for the non-declarative and declarative systems, respectively.

The explicit memory system is a conscious, analytic and reflective system which deals with facts, episodes and rules (Evans, 2008). When used for categorisation of unknown objects, this system uses logical rules, searching for characteristics and typical details. This systematic approach suggests that objects are identified through feature-by-feature matching in reference to a generic example (Norman, Young, \& Brooks, 2007). In doing so, there are many details or units that need to be elaborated, a process which utilizes working memory. However, working memory has a limited capacity (Marois \& Ivanoff, 2005). With more than four variables to process at a time, working memory will be cognitively loaded (Ross, 1969; Sweller \& Chandler, 1991). Hence, the explicit memory system is limited by the low capacity of working memory (Lieberman, Gaunt, Gilbert, \& Trope, 2002; Marois \& Ivanoff, 2005). In 
turn, it is extremely hard, and sometimes even impossible, to process real time events in complex situations. One advantage of the explicit memory system is that knowledge processed in this system is possible for humans to verbalize and communicate. Thereby, it is possible to formulate explicit rules which are applicable for a novice (Dreyfus \& Dreyfus, 1986).

In addition to the explicit memory system, humans also have a non-conscious and nondeclarative system known as the implicit memory system (Berry \& Dienes, 1993). This memory system uses rapid, automatic pattern recognition to process information (Evans, 2008; Lieberman, et al., 2002). Implicit memories are formed as multimodal sensory patterns consisting of a snap-shot of what we perceive, even non-consciously, in a specific situation what we hear, feel, see and smell. In addition, the feeling of failure or success are also captured as part of the whole pattern, a so-called somatic marker (Damasio, 1994). Logan (1988) suggested that "subjects store and retrieve representations of each individual encounter ["exemplar"] with a stimulus" (p. 501). It is therefore feasible to suggest that each representation is stored in the implicit memory system as an unique holistic pattern (Björklund, 2008).

Using holistic pattern recognition as a way to solve problems or identify phenomena has been described in other writings as non-analytic reasoning (Norman, et al., 2007). This strategy is based on similarity to previously encountered exemplars. As we re-experience a similar situation, the implicit memory system performs an non-conscious pattern recognition to help us feel and act in the same way as we did the last time that we encountered the same situation (Lieberman, 2000). It follows, that automatic action initiated by pattern matching, makes the implicit memory system rapid (Lieberman, et al., 2002). Hence, it should be noted that pattern matching functions do not employ working memory, which implies that the 
implicit memory system does not suffer from constraints such as cognitive load (Evans, 2008).

\section{Observational skill}

Humans' vision field is very narrow. We are only able to consciously focus on a small area, just one detail at a time (Bullier, 2001; Milner \& Goodale, 2008). To detect several objects in a large visual scene, we need to consciously change our focus. However, it is not clear how humans locate and select which objects to attend to.

By studying human behaviour, Milner and Goodale (2008) identified two anatomically separated vision systems. The first system is named "vision for perception" and is active when

people consiousely look at an object trying to identify it. However, when people act, for example, when they are moving their hand to manipulate an object, this system is not used to control the actions. Contrary, they use an anatomically separated cortical system that provides "vision for action". When "vision for perception" is used, it is only possible to perceive details which are in focus. In "vision for action" the periphery is relatively well represented which gives an oppurtinity to detect objects in a large visual scene (Milner \& Goodale, 2008).

Furthermore, when a situation, which has been encountered before and stored in the implicit memory system is re-lived, pattern matching functions direct our conscious vision to details that are of importance in a specific situation (Chun \& Jiang, 1999; Maljkovic \& Nakayama, 2000).

\section{Aim of the study and research questions}

To our knowledge, field work studies focusing on teachers are rare. Field work studies usually focus on the students while studies about teachers are conducted as classroom studies.

\section{This study aims to investigate expert teachers' observational skills in a complex learning}

environment, in this case, during a nature field excursion. By observational skill we mean both being able to discern features in nature relevant for biology education, but also to 
interpret the students' behaviour in terms of interest, attention, motivation, interaction and engagement in a learning process. The following research questions have guided our study:

1. How do teachers teach observational skill to their students?

2. How do expert teachers identify natural objects during an ecology field excursion?

3. In what way do teachers' observational skills impact their ways of teaching?

\section{$\underline{\text { Methods }}$}

\section{Research process}

The research design of the present study was governed by a theoretical framework consisting of the psychological model of the dual memory system. In contrasting the theoretical model with the empirical data obtained, we discovered inadequacies which made us go back to the literature to refine the model. This is referred to as an abductive approach. "In studies relying on abduction, the original framework is successively modified, partly as a result of unanticipated empirical findings, but also of theoretical insights gained during the process" (Dubois \& Gadde, 2002, p. 559). Hence, we argue that the present study offers new theoretical insights as well as empirical results pertaining to the dual memory system model.

\section{Context of the study}

Two experienced science teachers at university level were chosen to participate in the study due to their reputation as expert teachers and biologists by their colleagues. Carl and Eric (pseudonyms) have both worked as teachers in their present workplaces for more than ten years and have extensive experience in outdoor education. In addition, Carl is passionate about birds, and is always seen carrying his binoculars. Eric is a science teacher, teaching preservice teachers for preschool and compulsory school, while Carl teaches both biology students and pre-service biology teachers for secondary and upper secondary school. They work on different campuses in Sweden. Before the data collection, the teachers had been 
informed that the researchers were interested in how teachers handle a complex learning situation.

The content of the two excursions were largely similar. However, the student groups were different. Eric's group consisted of 12 pre-service science teachers for pre-school and primary school. The excursion took place in early autumn in a natural environment in southern Sweden that surrounds an oligotrophic lake. During the excursion, Eric and his students classified soil, searched for geological traces of the last glacial period (10 000 to 13000 years ago). During this period, Scandinavia was covered with an ice sheet that was 3-4 Deleted: when an ice sheet covered 1 kilometer thick and depressed the land mass. The land was then covered with sea water, except for the highest areas. The Highest Coastline is an indication of where the sea level used to be with respect to the land. This is an important concept in Scandinavian ecology. After the ice melted, land masses have risen and the Highest Coastline is difficult to discern nowadays in nature since it is no longer adjacent to the sea. The vegetation above and below the Highest Coastline differs since the degree of sea turbulence had a significant impact on the composition of the soil. Eric also let his students walk in a peat bog while looking at the specific plants growing there and exploring the natural surroundings. The excursion consisted of both one-way communication where Eric described the environment to the students as well

as particular episodes where the students actively explored the habitat. The students solved smaller tasks on their own or in groups. The excursion lasted for six hours including breaks for coffee and lunch.

Carl's group was a mixed group consisting of both prospective biologists and biology student teachers preparing for upper secondary school teaching. This excursion also took place in early autumn in a different part of the same region as Eric's group. There were episodes in the excursion which had a lecture-type character where the students gathered to take notes about what Carl talked about. There were also episodes in which the students were 
active in group work, where different groups worked with exploring and investigating the plants and the soil of the area. Overall, classification of soil types was an important component of Carl's excursion. Carl also discussed nature conservation, traces from the last glacial period. Moreover, he talked about the IUCN (International Union for Conservation of Nature) Red List of Threatened Species and in what way signal species could be used to trace rare species. Carl's group visited a forest, a clear-cut area, a Dystrophic lake, a peat bog. There they also talked about the plants living in the peat bog and the humification of organic matter. Lastly, the group visited a pasture. The excursion lasted for nine hours including coffee and lunch.

Since both excursions took place during the autumn, the weather was cold in the morning. At midday the temperature was comfortable, allowing for the removal of heavy jackets or coats. The sun shone throughout the day during both excursions. The vegetation in the region was still coloured green and bird and animal species were active.

\section{Data collection}

Eric and Carl were video and audio taped during the excursions. The audio recorder was worn by the teacher and recorded data constantly for entire duration of both excursions. The teachers were video recorded when they were teaching, using a student perspective. In addition, field notes were made and photographs were taken with a digital camera. We used all collected data to re-create the chronology of both excursions.

During certain episodes of the excursion, Eric wore a head-mounted video camera. To our knowledge, this approach has not been used in these kinds of studies. The purpose of this data-collection method was to capture the view of the teacher, a perspective previously proposed (but not employed) by Ainley and Luntley (2007). When we used the video captured by the head-mounted camera in the stimulated recall interview, the teacher was given the opportunity to recall the specific situation. By offering the interviewee a similar experience 
from the same angle as when he actually experienced the situation, we believe that this directly stimulates pattern matching in the teacher's implicit memory system.

Shortly after the excursion, the researchers identified interesting episodes in the collected data (Ainley \& Luntley, 2007). Shorter episodes were selected and fully transcribed. The starting point for the choice of episodes was the original dual process memory model. In accordance with Ainley and Luntley (2007), we searched for situations in which we believed that the teachers used tacit knowledge. We also sought for examples that illustrated how the teachers tried to "teach" their observational skills to the students on different levels, ranging from discerning details to recognizing abstract patterns in the surrounding nature.

Following this search in the data, the teachers were interviewed in a stimulated recall setting (Lyle, 2003). The episodes were represented by video clips from the video camera, the head mounted camera, or photographs from the digital camera composed altogether in the form of a slide show. A written interview guide was produced to support the interviewers. When we showed a new video clip the initial questions were open and neutral ("Could you comment on what happened here?") and later on, the questions became more focussed ("How do you know how to walk on a peat bog?"). The stimulated recall interview was also video and audio recorded. Both authors were present during the interview and posed the questions.

\section{Data Analysis}

The data treated in the study consisted of the researchers' own observations, field notes, video and audio recordings from the excursions as well as the stimulated recall interviews and photographs. To obtain an overview of the extensive material, the field notes were used as a starting point for writing content logs (Lindwall, 2008). By considering the video footage, the content logs were extended. The content logs were then utilised to expose episodes that indicated when we believed that the teachers acted in accordance with their tacit knowledge. Indications of automaticity and rapid, holistic identification of phenomena were also 
particular cues that we actively looked for. We employed statements from the stimulated recall interviews to corroborate our tentative selections obtained from viewing the video footage from the excursion. In turn, evidence from the stimulated recall interviews also served to validate our earlier impressions of the data as well as provide new directions for what to search for in the field data. The episodes from the data revealed limitations in the original dual memory model and called for an extension. By using an integrative literature review (Cooper, 1984) and the results from our empirical findings, the theoretical model was refined. This will be elaborated in the discussion section of this paper.

\section{$\underline{\text { Results }}$}

\section{Observational skill in nature}

The two teachers, Eric and Carl, are both using different strategies to identify natural phenomena, such as recognizing different species. In the following section, we present examples from teachers' strategies to talk about how to identify particular natural phenomena as well as their own strategies to identify it. The examples are obtained from the excursions and from the stimulated recall interviews conducted with both teachers. The examples presented in this section were chosen as typical from a larger sample of similar episodes. The examples were selected to answer in what way the teachers identified natural objects themselves and in what way they taught the students how to make the idenfication. This corresponds to the first and second research questions.

One example from Eric's excursion illustrates the teaching of the concept of a quagmire. During this event, he took his students to a peat bog and encouraged them to walk, and literally "feel the ground tottering beneath one's feet". At this point, Eric casually walked out into the peat bog and was followed by the students. The following extract shows how he gave clues about how to walk in a peat bog: 
Eric: And if you listen, you can feel... hear water oozing between... these floes of moss, or bog, or moss, or peat bog. And one could tell from the vegetation where you could walk or not.

However, the students failed to establish a "safe" path and began to sink. Although Eric had provided clues about how to walk on the peat bog with dry feet, it became obvious that those rules were of no direct use for the students when it came to the actual situation. In the stimulated recall interview, a question as posed to Eric about how he knew where it was safe to walk:

I: How do you know where you could walk or not?

Eric: The vegetation tells you where to put your feet. Sedges indicate that it's dryer.

And then one recognizes what kind of moisture there is.

The above datum illustrates an analytical, conscious answer upon which Eric attempted to explain his locomotion in the bog. However, this type of instruction could be rendered useless as guidelines for students, since it would be hard to know what was meant by, for example, "the vegetation tells you where to put your feet". Eric then continued:

Eric: It is trial and error. You may probe and you will see. From experience you know where you cannot go because you will sink. It's obvious.

Eric has walked on peat bogs many times before and when he relived an earlier experienced situation, it may have helped him to make the correct decisions. Eric had an intention to let the students experience what it is like to walk on a peat bog. From the stimulated recall interview, Eric highlighted the importance of being “out there", experiencing the tottering of the ground. He believed that the actual lived experience is of greater value in understanding the concept of a quagmire, than would read about it in a textbook, as shown in the following excerpt:

I: Why did you want them to go out there? 
1

2

3

Eric: I wanted them to have the experience. It's not the same thing to read about it in a book. It's different to really be out there and feel what it is like to walk on a quagmire.

The following episode was captured when Eric discussed soil classification with two students. In the following example, Eric refered to known everyday patterns that involve more senses apart from vision alone.

Student: It's kind of sand, eh... silt.

Eric: Yes... It feels very soft, but it crunches when I listen and now I have to taste...

S: It feels more like sandy soil then, or? If it crunches?

E:Yes... This is... yes it is Stomatol to me and then it's sandy soil.

S: It's sandy soil. Finer than this, when it's more like... When we think it's more like clay, then it is more like silt.

E: Then it's silt and then it's like potato flour, if you imagine...

$S: M m$.

E:...The consistency, thickness.

With respect to the datum above, Eric used sight, hearing and touch to identify the grain size of the soil. He looked at the grains, he listened to the "crunch" as he squeezed the grains between his fingers and he placed the grains in his mouth and used his tongue to feel the grains against his palate. As he talked about these actions with the student, he refered to experiences from everyday life, such as Stomatol toothpaste and potato flour which contain grains of different sizes. By comparing the different samples with this mental reference library, a categorization could be made. However, as shown in the excerpt, this is certainly not an easy thing for the student to interpret. Eric needed to transfer his interpretation to the student, by offering her sensory experiences which he could help her to label. The difficulty in identifying grain size was also apperent in the stimulated recall interview. In this regard, Eric talked about clay, which is the finest inorganic material in soils: 
Eric: If you take this piece and put it into your mouth you don't feel anything, if it only floats out in a way, like sour cream. This is clay. [...] It has taken quite a long time for me too to accept that in clay I don't feel any grains. It's just a... soft pulp.

Here, Eric talked about the procedure through which different soil grain sizes may be identified. Since the grains are microscopic, they are impossible to detect with our senses. That is, the absence of perception of grains through our sensory system would be an indication of clay. In this case, Eric did not have the ability to actually verbalize his knowledge explicitly.

In one part of Eric's excursion, the group passed the Highest Coastline. Since the Highest coastline is gradual, it is only possible to "see" if you are either above or below the line. Eric directed his students' attention to specific phenomena along the path, which together, provided indications about the groups' position in relation to the Highest Coastline. Eric highlighted important differences in geology and vegetation on each of the two sides. For example, Eric explained to the students:

Eric: We are approaching the Highest Coastline. [The group begins to walk]

Eric: Hey, here you have an old shoreline which we pass on this level. There are piles of pebbles on both sides. The fine materials have been ablated. Then you have this flat rock on your right, and you can see that there are no... well, it's pretty much bared all the time. Some [week] pines at the top. [They continue to walk]

In this quotation, Eric pointed out and labeled natural objects that are important in determining whether one is positioned above or below the Highest Coastline. He pointed to the old shoreline which is characterized by piles of pebbles and the absence of fine material. He also pointed to a flat rock which is almost bared. There were some weak pines growing there. Eric's comment that the pines were weak is his way of communicating that there was not much soil on the flat rock. Thereby, this was an example of how vegetation and soil 
depended on each other. In summary, the excerpt above generated from Eric provided explicit rules about how to identify areas "below" the Highest Coastline. During the walk, the group made four stops where Eric pointed out these different aspects. He provided several examples at each stop. Finally, Eric paused to pose a question to the students:

Eric: Have you noticed changes in the environment?

Student: It's more humid.

Eric: It's more humid, yes. And the tyre tracks are deeper. More humid and which rascals have entered?

Student: Blueberry.

Eric: Blueberry. Pretty high blueberry it is. What could be the cause for this change in the environment? [...] We are above the Highest Coastline.

In this quotation, Eric did almost the same thing as in the previous quotation. As the group was now above the Highest Coastline, he pointed out and labeled three different aspects, the humidity of the ground, wheel tracks and the appearance of blueberry (Vaccinum myrtillus). Above the Highest Coastline, finer materials have not been flushed away by the water. Therefore, the ground was covered with a thicker layer of nutritious soil that bound moisture, which resulted in deeper tracks produced from tyres and gave better conditions for vegetation, which Eric also mentioned. Noticeably, Eric used comparisons as he talked about the environment. He talked about higher humidity, deeper tyre tracks and in the following quotation he proceeded to talk about more or less vegetation on the flat rocks:

Eric: If you look at the flat rock on your left hand side you may notice that if it had been located below the Highest Coastline, it would have been bare. But it's covered with sprigs and has a layer of soil. We are above [the Highest Coastline], but it's hard to tell where the exact border is. 
During delivery of the verbal datum above, Eric pointed at a flat rock, recapitulating that it would have been bare at lower grounds, below the Highest Coastline. He then explained that since sprigs are growing on that flat rock, indicating a soil layer. Thus, Eric used the mental reference library which he had built up on their way up above the Highest Coastline, to make comparisons on what it looked like above and below the Highest Coastline, respectively. However, we would also emphasize that these rules are not easy to follow, trying to figure out if you are below or above the Highest Coastline. As Eric climbed his way up, he showed indications of not using the details that he gave to the students. We believe that he made a rapid categorization based on pattern recognition to decide wether he was positioned below or above the Highest Coastline.

In the following episode, Carl talked to a small group of students about how to recognize the grass species Calamagrostis arundinacea. He pointed at a small tuft of hair which appeared where the straw left the blade. He also pointed out that the grass was rather large and had broad blades.

Carl: Look where the blade leaves the straw. There are tiny hair tufts. Do you see it? Very easy to recognize. And then it's [the grass] pretty large and has broad leaves. This is Calamagrostis arundinacea.

Here, Carl was referring to a specific feature which discriminated this species from others. We suggest that this feature may function as a verbalized rule to induce the students to identify the grass on their own. However, as he approached the next group of students, and showed the same grass, the tuft of hair was not visible, as the following quotation shows:

Carl: You have this very tall grass. Large tufts with high, panicles standing together. And if you pull one up and look here. [...] Here, exactly where a leaf leaves the straw, down here in the edge, usually there are tiny hair tufts there. Now it was too wet to be seen properly. 
1

2

3

4

5

6

7

8

9

10

11

12

13

14

15

16

17

18

19

20

21

22

23

24

25

26

27

28

29

30

31

32

33

34

35

36

37

38

39

40

41

He explained to the students that usually, the hair tuft is easily found. The one character that he wanted the students to learn was missing in this particular exemplar. Therefore, Carl provided a second strategy to identify the grass:

Carl: The easiest way of sorting this out [...] if you are going to classify a grass, is to find a distinct tuft of grass that you have identified, and compare it with... Here you have such a reference for Calamagrostis arundinacea. You know that this is

Calamagrostis arundinacea. [...]Otherwise this could be almost impossible.

By comparing the unknown grass with a known reference tuft, identification was made possible. This is an example of where Carl changed strategy from discerning details to make a comparison, not feature-by-feature, but rather object-by-object. In the following excerpt from the stimulated recall interview, Carl revealed that he does not use either of these strategies when he identifies the grass:

I: [...] You recognized... [Carl: Yes]... from the overall [Carl: Yes], rather than from this hair tuft?

Carl: Yes it's where it is located and things that are much harder to communicate by telling... It's more from experience that you know... not always, but in many cases you know at least the most common species, [...] just from the environment. [...] You know approximately what you should find, and it just pops-up that it is that one. So of course, I know even without the hair tuft.

Carl said that he did not use the hair tuft, or the comparison, for identification. He merely identified the grass by familiarity, in which the environment also had a great impact. He also emphasized that it is hard to verbalize and that his knowledge is based on experience. Carl also said that as he recognizes a species in its specific environment, the idea of which species it is just "pops-up". 


\section{The impact of observational skills on teaching}

The following section aims to answer the third research question; in what way do teachers' observational skills impact their ways of teaching. In several episodes, there were indications that the teachers adjusted their teaching to the students' mode. We infer this as they had observational skills regarding their students. These observational skills influenced the teachers' behaviour. For example, the video recording revealed that the students were tired and had problems staying focused. Carl caught the students' attention, talked about the use of blue clay as make-up. By using this anecdote, Carl cheered the students up and made them focus.

Eric also used certain strategies to cheer the students up. After lunch, Eric began to show geological maps of the environment, which was captured on video. As he noticed that the students were tired, not paying attention, he interrupted his talk and started to sing a song about a tree and an owl. The song generated a lot of laughter and conversation amongst the students and they then became more focused and ready to continue with the excursion. Eric had planned to sing a song or two during the excursion.

The common feature for the presented examples was that the teachers acted by using verbal communication. There were also examples of non-verbal communication, where the teacher used gestures to draw the students' attention to a specific object (Figure 1).

Eric wanted to show the rocky bottom, which is typical for oligotrophic lakes (Figure 1A). At the shoreline, there were only sand and no visible rocks. Eric talked about the bottom, which was out in the lake and drew students' attention away from the shoreline: He pointed at the lake and moved closer to the lake and thereby encouraged the students to imagine what the bottom would look like out there. The students responded by moving closer and gazing way out on the lake. There was a gaze shift when Eric looked at what the students looked at (Figure 1B) and when the students followed his gaze out on the lake (Figure 1C). 


\section{[Insert Figure 1A-C about here]}

The following episode shows in what way Carl's observational skill of birds automatically directed his actions (Figure 2). Carl's plan was to introduce the old forest in which the students had gathered, sitting on a log, at the beginning of the excursion. $\mathrm{He}$ pointed at specific objects characterizing this type of surrounding. In this example, we want to show in what way the nature as such will impact the teachers' way of talking and acting. Carl started by pointing at and talking about the slope which is covered with moss (Figure 2A). However, suddenly a bird interrupted his communication with a lively twitter, which made him turn his head towards the bird and give a comment (Figure 2B). In doing so, he hesitated and thereby needed to find out how to continue his talk. He looked at the environment (Figure 2C) and picked up the previous thread, continued to talk about the rocks. While Carl pointed at and talked about the stones on the ground, he suddenly looked up to the trees (Figure 2D). It is likely that he had seen another bird, but he did not mention anything about it. Clearly, he was interrupted which made him hesitate once more, sweeping the slope for new triggers on what to talk about (Figure 2E). He even repeated a previous verbal output by describing the slope. This example shows that the context may control the behariour of the teacher. We believe that this behaviour was non-conscious and not reflected upon.

[Insert Figure 2A-E about here]

In the following example, Eric was interrupted by a bird as he was talking about the grove:

Eric: This is deciduous forest. In this environment [turns his head] it is grove vegetation. This creek [which they have already passed] is worth preservation because in the winter the grey wagtail and... or the grey wagtail... but the dipper... because of the open water here. 
The group had left the small creek and reached a grove, which Eric discussed with the students. Suddenly, a bird twittered, and in that moment, Eric turned his head and interrupted his description of the grove. He commenced with a new topic, in which he returned to speaking about the creek, talking about the birds that depended on the creek environment. When we asked about this sudden turn in the stimulated recall interview, it appeared that his initial plan was to talk about the birds as the group passed the creek. However, on this particular day, he did not do so and as they came to the grove he suddenly remembered that he had forgotten the birds. However, it seems that Eric was not consciously aware of the twittering bird, since he did not remember, not even after having being shown the specific video clip during the stimulated review interview. The fact that he did turn his head in direction to the bird's song indicated that he heared the song, even though it was on a nonconscious level.

\section{Discussion}

The present study has shown that the teachers used two different strategies to teach the students how to identify natural objects. The first strategy was to give the students rules, or specific characteristics. The second strategy was to draw comparisons between the unknown object or species and a familiar object. Within this strategy, there were three different ways in which the teachers made comparisons. i) They compared one exemplar with another as in the case with the grass Calamagrostis arundinacea in which an unknown grass tuft was compared with a known exemplar of the specific species. ii) They built a reference library, such as when Eric showed the difference in the environment below and above the Highest Coastline, respectively. iii) They also used known references from everyday life as Eric for example compared sense of granularity of the soil with a sandy beach, Stomatol toothpaste and potato flour. These comparisons all have in common that they compared the whole sensory experience of two different exemplars. We have also identified teachers' automatic behaviour 
both as they walk on a peat bog and as they manage the teaching situation. In the following sections we will discuss those findings in relation to the dual memory system model.

\section{Teaching strategies for identification of natural objects}

We have identified two different strategies in which the teachers taught how to identify different natural objects. These strategies have been described earlier as two different types of category learning (Hammer, Diesendruck, Weinshall, \& Hochstein, 2009).

The first strategy was to identify specific characteristics that discriminated one exemplar from another. This strategy was used when it was possible to express the message verbally. An example from this strategy was when Carl first introduced the Calamagrostis arundinacea to the students. The small hair tuft was a feature which was possible to talk about. In making a feature-by-feature matching against a generic example (Norman, et al., 2007), it is possible to identify different species. This approach is a typical process of the explicit memory system (Evans, 2008), which makes it possible to verbalize and communicate. Since this approach was expressed as a rule it is usable to a novice (Dreyfus \& Dreyfus, 1986).

The second strategy was to compare one species or natural phenomenon with familiar objects or phenomenon from everyday life. This strategy is used when it is not possible to compartmentalize different features without losing the general impression. Within this category, we have identified three different ways of making comparisons. We suggest that, while looking at the reference, the students temporally store a priming template in implicit memory system (Chun \& Nakayama, 2000). This priming template can then be used in a pattern matching process. The third strategy was a little bit different since the teacher used references, which he assumed that the students have had previous experiences about.

However, all strategies were based on holistic pattern recognition, People are able to identify a specific natural object effortlessly without analysing features. Since they have acquired a 
large number of exemplars, they are able to make an non-conscious similarity match (Norman, et al., 2007). In the first two cases, the students did not have their own patterns of the natural objects, and thereby the teachers have to give them references, whilst in the third case they are assumed to compare with known objects. We propose that using comparisons is a way to develop observational skill for natural objects.

In the direct communication with only two students Eric was able to respond to the students' understanding of sandy soil and refine the references. Eric used several senses to identify sandy soil and to provide the opportunity for the students to follow his line of argument. During the whole excursion, he had dug holes for soil classifications, thus building a reference library. He used references from everyday life to put labels on the different sensory experiences, as Stomatol toothpaste or potato flour. In this example, Eric used both features and comparisons. We would suggest that the sensory experiences made it possible for the students to form implicit memories. Furthermore, we strongly believe that these memories may be linked to a label in the explicit memory system. As Eric repeated the exercise several times, the students' forming of implicit memories should be enhanced. Since implicit knowledge has shown to be more long-lasting than explicit knowledge (Dennis, Howard Jr, \& Howard, 2006; Jenkins \& Hoyer, 2000), this may mean that the students will feel familiarity with the object even if they have forgotten its declarative label. This is similar to when people recognize each other but have forgotten respective names. On this score, a follow-up study by the present authors is investigating the retention of the students' implicit and explicit knowledge, respectively, and the link between these (Stolpe \& Björklund, in progress).

When Eric talked about the Highest Coastline, both teaching strategies are apparent. When Eric was below the Highest Coastline, he mentioned several features which he wanted the students to direct their attention to. As he emerged above the Highest Coastline he mentions the moisture of the ground, deep tyre tracks and blue berry. He also wanted the 
students to look at the flat rocks, which above the Highest Coastline were not bare. In accordance with the second strategy, he also made comparisons between specific features of the environment below and above the Highest Coastline, respectively. He tried to give examples and verbalize his explicit knowledge to the students. However, the rules given were not much of a help for the students to identify the complex object of the Highest Coastline. According to Zeithamova and Maddox (2006) it is not possible to consciously focus on more than one characteristic at a time, due to cognitive load constraints (Marois \& Ivanoff, 2005; Sweller \& Chandler, 1991). But, Eric also offered the students multimodal patterns of what the environment looked, smelled and felt like above and below the Highest Coastline. Thereby, we suggest that the students may store these holistic patterns as implicit memories which could be later used to recognize similar patterns.

Our results show that the teachers used a systematic and analytical way of identification as they teach this to their students. However, we would argue that the teachers offered deliberate practice to their students. Deliberate practice is characterized by well defined tasks, informative feedback, repetition, self-reflection, motivation and endurance (Moulaert, Verwijnen, Rikers, \& Scherpbier, 2004). Since deliberate practice is the basis for formation of implicit knowledge, we would suggest that this may be a good way of teaching a more rapid and global strategy for identificiation. Our results show that this is the strategy that the teachers used themselves and this will be discussed in the following section.

\section{Non-analytic identification of natural objects}

Both Carl and Eric had an ability to identify species, geological and biological phenomena and to walk on a peat bog. We would claim that this non-analytical recognition of holistic patterns was used by the teachers in all situations with which they had lots of experience. The ability to categorize natural scenes through global properties and not by details and features has earlier been described by Greene and Oliva (2009). They also show
Deleted: . Furthermore, it is not possible to process too many features in working memory

Deleted: are all important factors 
that such categorization is rapid (see also Griffiths, 2010; Thorpe, Fize, \& Marlot, 1996), which indicates that the implicit memory system is involved in the process (Chun \& Jiang, 1999). Taken together, these results suggest that holistic pattern recognition, which is shown by the teachers in the present study, is a result of learning by the implicit memory system.

Deleted: implicit

We would argue that Eric did not consciously analyze the depth of the soil layer on the flat rocks nor did he look for the old shore lines since he was below the Highest Coastline. We suggest that this example illustrates observational skill of an expert. We would further claim that the process of holistic pattern recognition employs a knowledge-base of earlier encountered situations that already exist stored in the implicit memory system (Björklund, 2008; Evans, 2008; Logan, 1988; Norman, et al., 2007). Eric's implicit memory system holds several earlier exemplars of what nature looks like below the Highest Coastline. The implicit memory system will automatically detect similarities in the encountered situation and facilitated Eric's identification of the environment.

Carl recognized the grass Calamagrostis arundinacea by familiarity, without looking at the small hair tuft. He even mentioned that this is a skill which is hard to explain and which is based on experience. The name of the species just "pops-up". With respect to this finding, our conclusion is that Carl used non-analytic pattern recognition, one that used implicit memories of encountered exemplars of this particular grass. Such a process is a non-verbalized and tacit knowledge. However, we suggest that when such pattern matching occurs, an explicit memory of the name and details of that species will be triggered, a declarative knowledge, which in turn, is possible to verbalize. As the total environment was part of Carl's identification, we would claim that this is an example of holistic pattern recognition.

It is also plausible to infer that the same line of argument is true for Eric's classification of soil. In the stimulated recall interview, Eric experienced problems in verbalizing in what way he deduced the classification of clay. This indicates that the knowledge was implicit and 
that it is not even possible to elucidate the feeling of clay into details that are possible to discern with our senses and explain verbally.

At first glance, it appears that we are talking about two different skills, identifications of large structures, here represented by the trophic level of a lake and the Highest Coastline, or small structures in nature, as identification of species such as grass or mosses. However, we claim that the underlying cognitive mechanism for these skills is the same, namely implicit memory matching. Both large and small structures are identified through holistic pattern recognition, which in turn, is based on earlier experiences.

\section{Behaviour as an automatic response}

We claim that when Eric walked on the peat bog knowing exactly where to put his feet without getting wet, he acted in accordance with previous "sinking" experiences that had been stored in his implicit memory system. On a non-conscious level, he recognized the dangerous as well as the safe paths and acted automatically (figure $3 \mathrm{~A}$ ). He recognized the specific situation and acted intuitively in accordance to sensory experiences that included the wideangle view of his implicit memory system. During the interview it became clear that this was a skill which he could not explain nor describe, "it is trial and error". He knew that he used some knowledge that he was not aware of; in Polanyi's words: "You know more than you can tell" (p. 4). Such knowledge is tacit, and stored in the implicit memory system.

The teachers responded to the students' behaviour during the excursion. When the students were exhausted, the teachers cheered them up and when the students were not alert the teachers paused to give them time to catch up. Eric had planned to sing during the excursion. The timing of when and whether he sang one or two songs was however, an automatic response to the mood of the group. This is all part of a teachers' skills of managing a class of students. We argue that these skills are needed irrespective of whether the lesson takes place inside a classroom or in a natural setting. We also suggest that it is the same 
cognitive processes that are triggered when an experienced teacher manages a classroom or when s/he identifies natural objects in nature.

In the example where Carl is disturbed by the wren (Figure $2 \mathrm{~A}-\mathrm{E}$ ), we argue that both the natural environment and the students are part of the holistic patterns which impact the behaviour of the teacher. From the beginning, Carl delivered a talk, according to his plan which could be described as an explicit, conscious act. As the bird started twittering, his previously stored acoustic patterns of wrens were activated, which made him interrupt his lecture and automatically attend to the bird (Figure 3B). The implicit pattern recognition made the explicit name of the bird "pop-up" and he told the students that they had disturbed the wren. Trying to reestablish the thread in his speech, Carl was now looking around the environment. In doing so, implicit patterns were activated, which in turn, triggered the topic of the lecture processed in explicit memory system. The implicit patterns of rocks and stones reactivated the explicit knowledge and induced him to talk about those objects. While pointing at the stones, Carl's attention was suddenly drawn up towards the sky. His conscious vision was directed by his implicit patterns. At this point, he did not mention anything to the students. However, as he hesitated, we infer that his explicit, conscious plan, which was processed in working memory, should be interrupted. The associations with the bird had replaced one part of what he had intended to say. Once more, Carl was sweeping, to recall his lecture. This non-conscious manoeuvre made him commence the communication all over again.

For the expert teacher, managing the classroom is, in many ways, an automatic action (Ainley \& Luntley, 2007). We will shed light on this process by suggesting that this behaviour is automatic since it is based on implicit knowledge which in turn is based on lots of experience. The teachers in the present study have many years of deliberate practice and experience from teaching out in nature and had developed automatic behaviour which 
controlled their actions in the teaching situations. Automatic behaviour has been connected to the implicit memory system (Evans, 2008). We propose that Eric's approach of drawing the students' attention away from the shoreline, pointing at the lake and encouraging them to imagine what the bottom of the lake looks like, was an automatic response. Since he nonconsciously observed that the students looked down in the water, trying to figure out what the bottom looked like, he used body language, walking closer to the water and pointing out in the lake (Figure 1). Such gaze shifts are an important social behaviour, which is based on implicit pattern recognition and automaticity. This behaviour can be compared with the expert teachers' intuitive behaviours shown in other studies (Ainley \& Luntley, 2007; Johansson \& Kroksmark, 2004).

This automatic action as a response to implicit pattern recognition also directs Eric's way of structuring his verbal communication (Figure 3B). The fact that he did turn his head toward the bird's song indicates that he did non-consciously notice the bird during the excursion. We suggest that the acoustic, implicit pattern of birds singing triggered the explicit topic of the bird and the creek. This topic is usually triggered as he passes the creek.

When it comes to teaching, we would argue that deliberate practice is a way to collect exemplars of teaching situations; when teaching works out well and when it fails, when students are interested and when they are not and when they understand or not. All these situations are stored as exemplars of particular situations. We will feel familiarity as a new upcoming situation is matched against one of the stored exemplars of the situation (Norman, et al., 2007). Since implicit memories are sometimes marked with an earlier outcome, a somatic marker (Damasio, 1994), an automatic and rapid response is possible.

We show two examples in which the teachers showed automaticity regarding both the natural surroundings and the students. We claim that the implicit memories disturbed the teachers as well as supported their teaching. When Carl was disturbed by the wren, his 
implicit memories of the bird made him lose control, which diverted him from his plan. In the same way, implicit memories were activated as he tried to regain the thread again. We would argue that the nature could function as an external script for the lecture. We suggest that the objects in the environment trigger the next explicit thought. Eric was disrupted by a bird in a similar way, which made him falter and talk incoherently. This behaviour was also seen by Ainley and Luntley (2007). We suggest that the hesitation is due to the activation of implicit memories. Thereby, we propose that the attention-dependent knowledge, introduced by Ainley and Luntley, is identical to implicit knowledge. This knowledge helps guiding the attention of the expert teacher, which is also described in earlier research (Berliner, 2001; Dreyfus \& Dreyfus, 1986; Johansson \& Kroksmark, 2004; Kerrins \& Cushing, 2000; Krull, Oras, \& Sisask, 2007; Sabers, et al., 1991). Since implicit knowledge is tacit, the teachers were unable to explain their behaviour for the students. However, in being there and experiencing how the teachers acted, the students learnt teaching strategies by example.

Furthermore, we suggest that the teachers reacted on things that they were not focussing on. For example, Eric reacted on that the students were not looking out on the lake and Carl looked for the twittering wren. This indicates that the teachers used a "wide-angle" view, which has been shown to facilitate implicit object recognition (Boucart, Naili, Despretz, Defoort-Dhellemmes, \& Fabre-Thorpe, 2010). We are of the view that implicit pattern matching may direct our conscious focus and could serve to explain how we locate objects (Maljkovic \& Nakayama, 2000). Our results support the idea of two separate vision systems, one "wide-angle" view and one consciously, narrow view. Milner and Goodale (2008) described those as "vision for action" and "vision for perception", respectively. However, we suggest that the "wide-angle" view is connected to the implicit memory system while the conscious, narrow view is explicit. "Vision for action" is used as we act, for example when Eric walked on the peat bog. 


\section{[Insert Figure 3A and 3B about here]}

\section{Conclusions and implications for teaching}

This study supports the idea of two complementary systems - the dual memory system.

The two expert teachers used pattern recognition to identify natural objects during the excursion. This pattern recognition is processed by the implicit memory system in which earlier encountered situations are stored. These implicit memories are then available for matching against a new specific situation. However, the teachers were using conscious, declarative strategies to teach, which are strategies connected to the explicit memory system.

We suggest that by using the modified dual memory system model we are able to explain ecological observational skill shown by expert teachers.

Another important function of the implicit memory system is its ability to control automatic behaviour in accordance with earlier experiences. This automatic behaviour, which is directly connected to expertise, does not strain working memory and hence limits the risk of cognitive overload. For example, we propose that the pattern matching mechanism of the implicit memory system controls our conscious attention and directs our visual focus. This is how we "know" where to look, which is an important part of observational skill.

We suggest that there is a constant interplay between the explicit and implicit memory systems. The pattern matching in the implicit memory system will trigger the label of the object in the explicit memory system and thereby make the name of the object conscious and possible to verbalize. The interplay between the two systems could then be seen as a tentative answer to Ryle's question of what starts our thinking process (Ryle, 1949).

Even though the objects of this study are two ecological teachers, we propose that our theoretical model (figure 3A, 3B) is of general interest for teachers at all levels, but more specifically for teacher educators. We argue that the underlying mechanism of observational skills in different contexts (e.g. teaching or ecology) could be explained by the dual memory

Deleted: In essence, this could be interpreted as an implicit pattern matching process that triggers our conscious thoughts in the explicit memory system.
Deleted: Still, while being out in nature, the teachers offered their students deliberate practice and first hand sensory thereby possible to predict that the

students would create implicit memories, which would facilitate the development of holistic pattern recognition and

Deleted: s

Deleted: Implicit memories facilitate non-conscious decision-making and judgment.
Deleted: exemplar 
system model. However, observational skill has to be trained in the specific context and is not a general ability.

We would argue that the teachers taught the students about the wood, talking about the

trees. However, by actually being out there, the teachers also offered the students a firsthand sensory experience which is a prerequisite for the formation of implicit memories. Through

this process, holistic pattern recognition and observational skill development was made

Deleted: is

possible. Overall, this research supports and emphasises the pedagogical importance of

learning about ecology through outdoor education. 
Ainley, J., \& Luntley, M. (2007). Towards an articulation of expert classroom practice. Teaching and Teacher Education, 23(7), 1127-1138.

Berliner, D. C. (2001). Learning about and learning from expert teachers. International Journal of Educational Research, 35(5), 463-482.

Berry, D. C., \& Dienes, Z. (1993). Implicit learning : theoretical and empirical issues. Hove: L. Erlbaum.

Björklund, L. (2007). The intuitive practitioner: Cognitive aspects on the development of Expertise. Paper presented at the 13 International Conference on Thinking, Norrköping.

Björklund, L. (2008). Från Novis till Expert:Förtrogenhetskunskap i kognitiv och didaktisk belysning [From Novice to Expert Practical Wisdom, Implication for Education from a Cognitive Perspective]. Doctoral thesis, Linköping University, Linköping.

Boucart, M., Naili, F., Despretz, P., Defoort-Dhellemmes, S., \& Fabre-Thorpe, M. (2010). Implicit and explicit object recognition at very large visual eccentricities: No improvement after loss of central vision. Visual Cognition, 18(6), 839-858.

Bullier, J. (2001). Integrated model of visual processing. Brain Research Reviews, 36, 96107.

Chun, M. M., \& Jiang, Y. (1999). Top-down attentional guidance based on implicit learning of visual covariation. Psychological Science, 10(4), 360-365.

Chun, M. M., \& Nakayama, K. (2000). On the functional role of implicit visual memory for the adaptive deployment of attention across scenes. Visual Cognition, 7, 65-81. 
Cooper, H. M. (1984). The integrative research review : a systematic approach. Beverley Hills ; London: Sage.

Damasio, A. R. (1994). Descartes' error : emotion, reason, and the human brain. New York: G.P. Putnam.

Dennis, N. A., Howard Jr, J. H., \& Howard, D. V. (2006). Implicit sequence learning without motor sequencing in young and old adults. Experimental Brain Research, 175(1), 153164.

Dreyfus, H. L., \& Dreyfus, S. E. (1986). Mind over machine : the power of human intuition and expertise in the era of the computer. Oxford: Basil Blackwell.

Dubois, A., \& Gadde, L.-E. (2002). Systematic combining: an abductive approach to case research. Journal of Business Research, 55, 553-560.

Ericsson, A. K. (2006). The Cambridge Handbook of Expertise and Expert Performance. Cambridge: Cambridge University Press.

Evans, J. S. B. T. (2008). Dual-processing accounts of reasoning, judgment, and social cogntion. Annual Review of Psychology, 59, 255-278.

Greene, M. R., \& Oliva, A. (2009). Recognition of natural scenes from global properties: seeing the forest without representing the trees. Cognitive Psychology, 58, 137-176.

Griffiths, T. D. (2010). Sounds familiar? Neuron, 66, 475-476.

Hammer, R., Diesendruck, G., Weinshall, D., \& Hochstein, S. (2009). The development of category learning strategies: what makes the difference? Cognition, 112, 105-119.

Jenkins, L., \& Hoyer, W. J. (2000). Instance-based automaticity and aging: acquistion, reacquistion, and long term retention. Psychology and Aging, 15(3), 551-565.

Johansson, T., \& Kroksmark, T. (2004). Teachers' intuition-in-action: how teachers experience action. Reflective Practice, 5(3), 357-381. 
1

3

4

5

6

7

8

9

10

11

12

13

14

Kerrins, J. A., \& Cushing, K. S. (2000). Taking a Second Look: Expert and Novice Differences When Observing the Same Classroom Teaching Segment a Second Time. Journal of Personnel Evaluation in Education, 14(1), 5-24.

Krull, E., Oras, K., \& Sisask, S. (2007). Differences in teachers' comments on classroom events as indicators of their professional development. Teaching \& Teacher Education, 23(7), 1038-1050.

Lieberman, M. D. (2000). Intuition: a social cognitive neuroscience approach. Psychological Bulletin, 126(1), 109-137.

Lieberman, M. D., Gaunt, R., Gilbert, D. T., \& Trope, Y. (2002). Reflection and reflexion: A social cognitive neuroscience approach to attributional inference. Advances in Experimental Social Psychology, 34, 199-249.

Lindwall, O. (2008). Lab Work In Science Education. Instruction, inscription, and the practical achievement of understanding. Linköping University, Linköping.

Logan, G. D. (1988). Toward an instance theory of automatization. Psychological Review, 95, 492-527.

Lyle, J. (2003). Stimulated recall: a report on its use in naturalistic research. British Educational Research Journal, 29(6), 861-878.

Maljkovic, V., \& Nakayama, K. (2000). Priming of popout: III. A short-term implicit memory system beneficial for rapid target selection. Visual Cognition, 7(5), 571-595.

Marois, R., \& Ivanoff, J. (2005). Capacity limits of information processing in the brain. TRENDS in Cognitive Sciences, 9(6), 296-305.

Milner, A. D., \& Goodale, M. A. (2008). Two visual systems re-viewed. Neuropsychologia, $46(3),, 774-785$. 
Moulaert, V., Verwijnen, M. G. M., Rikers, R., \& Scherpbier, A. J. J. A. (2004). The effects of deliberate practice in undergraduate medical education. Medical Education, 38 , 1044-1052.

Norman, G., Young, M., \& Brooks, L. (2007). Non-analytical models of clinical reasoning: the role of experience. Medical Education, 41, 1140-1145.

Ross, B. M. (1969). Sequential visual memory and the limited magic of the number seven. Journal of Experimental Psychology, 80(2), 339-347.

Ryle, G. (1949). The Concept of Mind (13th impr. ed. ed.). London: Hutchinson.

Sabers, D. S., Cushing, K. S., \& Berliner, D. C. (1991). Differences among Teachers in a Task Characterized by Simultaneity, Multidimensionality, and Immediacy. American Educational Research Journal, 28(1), 63-88.

Squire, L. R. (2004). Memory systems of the brain:A brief history and current perspective. Neurobiology of Learning and Memory(82), 171-177.

Stolpe, K., \& Björklund, L. (in progress). Students' long-term memories from an ecology field excursion: Retelling a narrative as an jnterplay between implicit and explicit

Deleted: excursion Formatted: Swedish (Sweden) Deleted: Deleted: The relation memories.

Deleted: learning

Sweller, J., \& Chandler, P. (1991). Evidence for cognitive load theory. Cognition and instruction, 8(4), 351-362.

Thorpe, S., Fize, D., \& Marlot, C. (1996). Speed of processing in the human visual system. Nature, 381(6), 520-522.

Zeithamova, D., \& Maddox, W. T. (2006). Dual-task interference in perceptual category learning. Memory \& Cognition, 34(2), 387-398. 


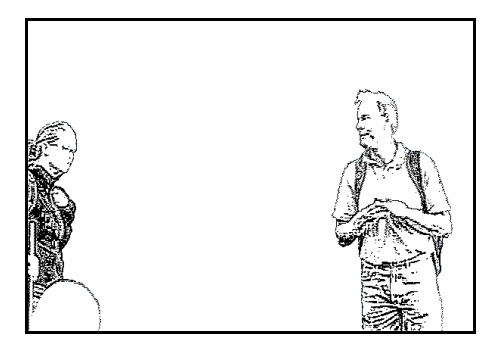

Figure 1A. Eric wanted to show the rocky bottom to the students. He talked about the bottom. Eric: What is the bottom like? [...]

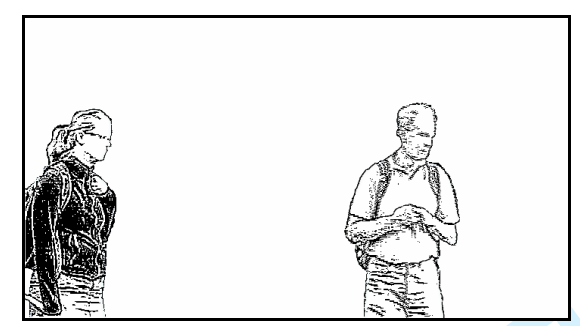

Figure 1B. Eric followed the students' gaze and saw that they looked at the shoreline instead of out on the lake. Eric: In this case, the bottom is sandy, and on other places there will be...

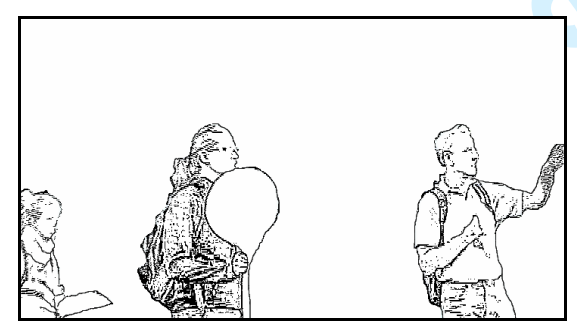

Figure 1C. Eric pointed out on the lake and drew the students' attention away from the shoreline. The students follow his gaze out on the lake. Eric: Well, we could imagine what it is like if we look out there. Then it's not sandy, but...

Student: Stone. 


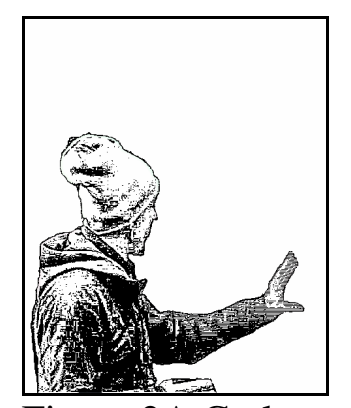

Figure 2A.Carl swept over the environment with his hand. Carl: When you look around, watching a slope like this. It's very nice and fancy with lots of mosses everywhere.



Figure 2B. Suddenly a bird's lively twitter interrupted his communication. He looked for the bird. Carl: You, oh... We have upsetted a wren.

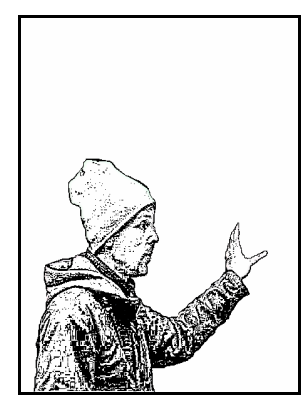

Figure 2C. He looked at the environment, and regained the previous thread. Carl: Eeeh... Anyway, you can see, there are plenty of rocks, plenty of stones...

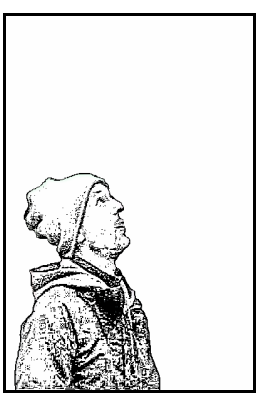

Figure 2D. Suddenly Carl looked up in the trees and continued to talk. Carl: ... and so on, which are here... 




Figure 2E. Carl was interrupted and hesitated and swept the slope for new cues on what he was talking about. Carl: And eh... In this kind of slope I think it's rather easy to imagine... 


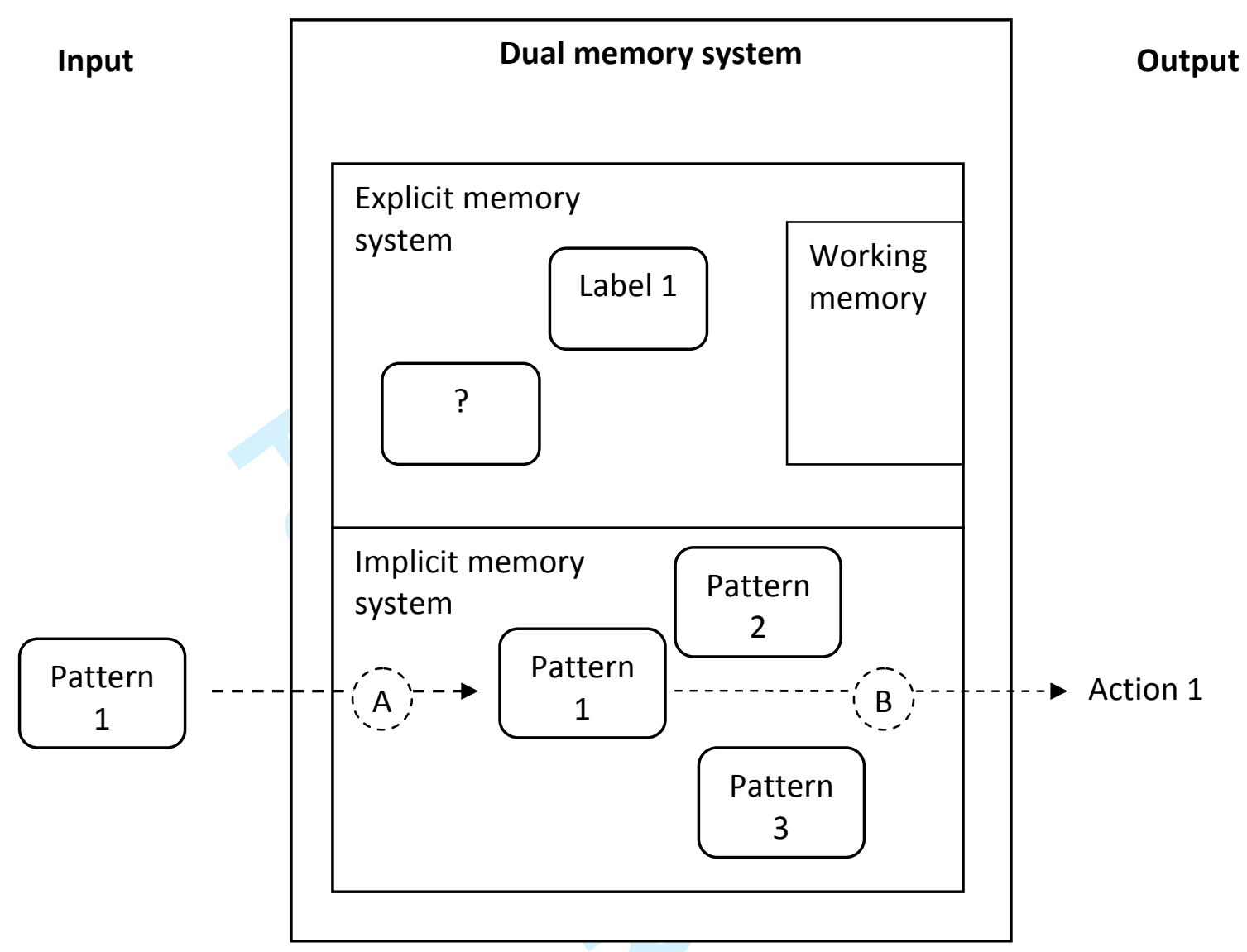

Figure 3A. Behaviour as an automatic response. In the pattern recognition process (A), an external stimulus is matched against one of the patterns of earlier encountered situations stored in the implicit memory system. This process activates (B) a specific action that for the individual through experience has proven to be useful in the specific situation. Since the process never activates working memory, the action will remain non-conscious. 


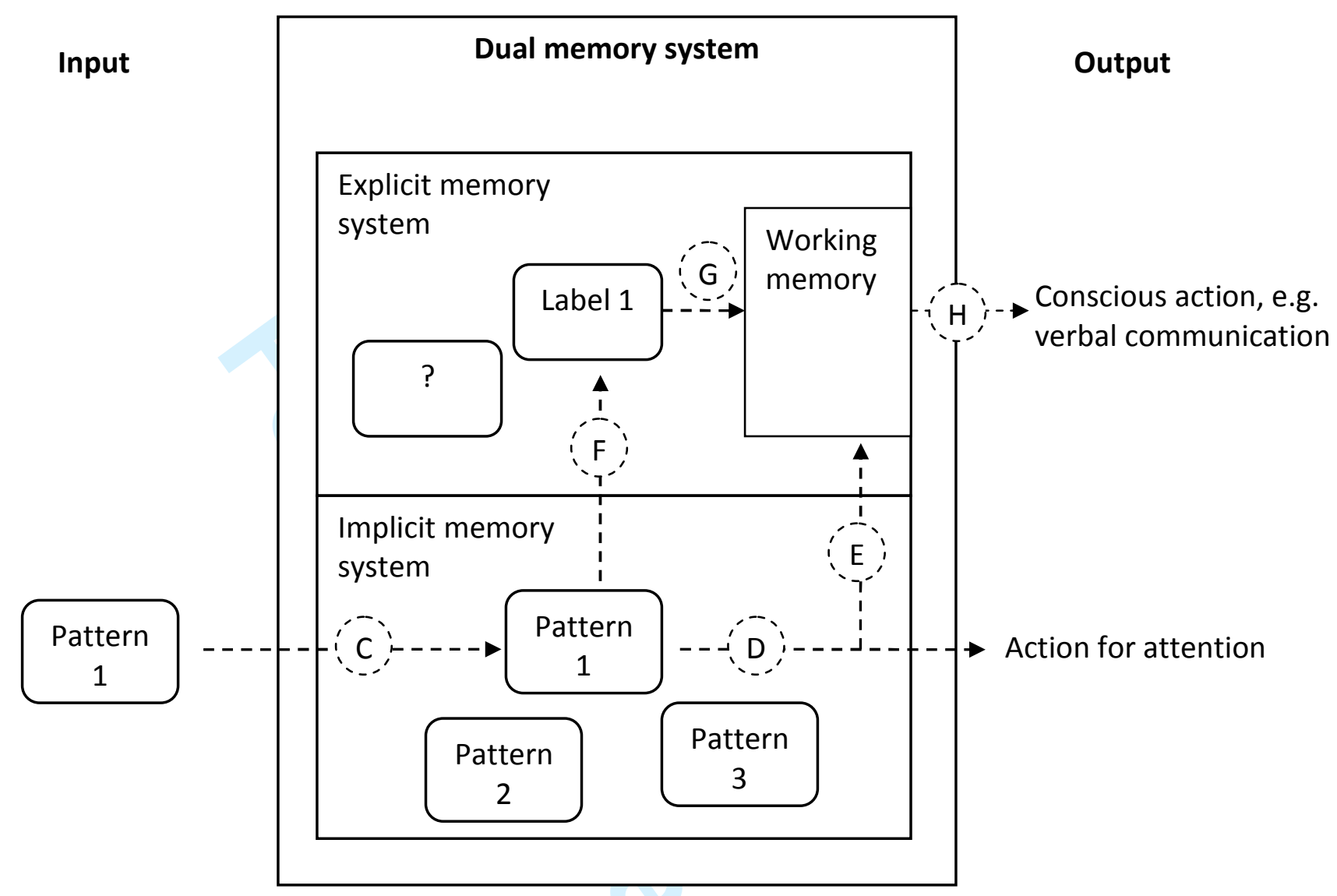

Figure 3B. Non-analytic identification. In the pattern recognition process (C), an external stimulus is matched against one of the patterns of earlier encountered situations stored in the implicit memory system. This process may lead to an action that directs attention (D) that is, turning the head and changing the visual focus. With attention, working memory becomes receptive $(\mathrm{E})$ for labels. These labels are activated by the pattern matching process $(\mathrm{F})$. Both attention and the activation of corresponding label are necessary for us to be conscious about what we attend to. When the label becomes available in working memory $(G)$ it is available for verbal communication $(\mathrm{H})$. However, there are situations when we have forgotten (or never had) the label. We will then only be aware of a feeling of familiarity. 